\title{
EXPLANATIONS IN MICROPHYSICS: A RESPONSE TO VAN FRAASSEN'S ARGUMENT
}

\author{
Silvio SENO CHIBENI \\ State University of Campinas (Unicamp)
}

\begin{abstract}
The aim of this article is to offer a rejoinder to an argument against scientific realism put forward by van Fraassen, based on theoretical considerations regarding microphysics. At a certain stage of his general attack to scientific realism, van Fraassen argues, in contrast to what realists typically hold, that empirical regularities should sometimes be regarded as "brute facts", which do not ask for explanation in terms of deeper, unobservable mechanisms. The argument from microphysics formulated by van Fraassen is based on the claim that in microphysics the demand for explanation leads to a demand for the so-called hidden-variable theories, which "runs contrary to at least one major school of thought in twentieth-century physics". It is shown here that this argument does not represent an insurmountable obstacle to scientific realism, not even when a series of important theoretical and experimental results against hidden-variable theories - and not merely a conflict with a certain school of thought - is taken into account.
\end{abstract}

The scientific attitude is that correlations cry out for explanation.

J. S. Bell (1981, p. C2-55)

It seems to me that we do not know ... enough, yet, to state with any conviction that [Schrödinger's] and Einstein's quixotic refusal to abandon classical standards of physical explanation was the act of heretics and sinners rather than of not yet canonized saints and martyrs.

J. Dorling (1987, p. 40)

\section{Introduction}

In epistemology, the anti-realists adopt a pessimistic stand toward the classical, Lockean problem of the extent of human knowledge; the scientific anti-realists are sceptical, in particular, about our power to discover, through scientific inquiry, unobservable causes of the natural phenomena. Given the fact that scientists in general are not intimidated by such a philosophical ban on research aiming at disclosing the hidden mechanisms of the world, we find in science and particularly in contemporary science - lots of theories that, on the face of

Principia, 12(1) (2008), pp. 49-71. Published by NEL — Epistemology and Logic Research Group, Federal University of Santa Catarina (UFSC), Brazil. 
it, offer tentative pictures of unobservable layers of reality. These theories are usually called explanatory theories, since, classically, to explain a phenomenon is to point out its causes. Phenomenological theories, in contrast, are theories that offer merely superficial correlations between the phenomena. Confronted with such a state of affairs, scientific anti-realists have proposed, among others, the following options:

i) To restrict science to phenomenological theories. This extreme position was adopted by Mach, for instance.

ii) To reinterpret the sentences of explanatory theories which, on the face of it, refer to unobservable items ("sentences about unobservables", for short), in such a way that they are deprived of any propositional content: they would, in fact, be mere linguistic instruments, useful in structuring the bona fide propositions of the theory (i.e. those referring to observable entities and processes). This position is known as instrumentalism.

iii) To reinterpret the sentences about unobservables in such a way that their propositional content is reduced, by means of appropriate translations, to phenomenological assertions. This is the form of anti-realism typically espoused by the logical positivists.

iv) To take at face value the sentences about unobservables, but regard the determination of their truth-values as lying outside the aim of science. This moderate form of anti-realism has been originally proposed by van Fraassen, under the name of constructive empiricism.

These positions are arranged in order of decreasing distance with respect to scientific realism. But in all cases science does not seem to attain one of its two classical goals: to explain the natural phenomena (and not just to predict their occurrence). This is plain in the first two positions; in the other two matters are more complex, since both have explicitly been associated with theories of scientific explanation. The logical positivists, as is well known, generally adopted the nomological-deductive view of explanation, according to which to explain is to subsume logically under general laws. As to van Fraassen, in chapter 5 of The Scientific Image he put forward a detailed "pragmatic" theory of explanation, compatible with the epistemological tenets of constructive empiricism. In both cases, however, the notion of explanation is much weaker than the classical notion. In both accounts, to explain a phenomenon demands no epistemic penetration into its causes, and therefore implies no real understanding of its occurrence. ${ }^{1}$ Scientific realists regard this as a serious shortcoming.

Scientific explanation is a central theme in the debate over scientific realism, not only because it introduces the cleavage that has just been indicated, but also

Principia, 12(1) (2008), pp. 49-71. 
because the explanatory power (in the classical sense) of a theory is often taken by realists as evidence for the theory's truth. Arguments for the truth of a theory based on its explanatory power are usually called abductive arguments (or, in another account, "inference to the best explanation"). Anti-realists generally do not acknowledge the epistemic validity of such arguments. Much of van Fraassen powerful attack on scientific realism, launched in The Scientific Image, depends on his systematic dismissal of several forms of abductive arguments. The aim of the present essay is to examine certain parts of this sophisticated criticism. Before going into details, I will summarise the four main steps of van Fraassen's criticism.

1. Van Fraassen begins by rejecting the direct application of abductive arguments. The fact that a theory explains a given set of phenomena should not count in favour of the truth of the theory, he holds, because estimates of explanatory power are deeply influenced by contextual factors (historical, cultural, psychological, etc.), and therefore cannot have any epistemic weight. Explanatory power should be regarded as a purely pragmatic theoretical virtue: it has to do with the relations of a theory to its users, not to the world.

2. Van Fraassen endeavours, then, to rebut two forms of sophisticated abductive arguments, Smart's "cosmic coincidence" argument and Putnam's "miracle" argument.

3. In case these refutations are regarded as unconvincing, van Fraassen argues that even if we concede that abductive arguments have epistemic legitimacy, such arguments are not effective in establishing scientific realism, because in science there are severe limitations in the demand for explanations. Scientific realists would, therefore, lack the opportunity of making abductive inferences.

4. As a final blow, van Fraassen puts forward a pragmatic theory of explanation, according to which explanation is radically disconnected from truth.

I consider van Fraassen's arguments against direct abductive arguments for the most part convincing, and will not comment on them here. ${ }^{2}$ Step 4 will also be put on a side here, but for a different reason: lack of space. The specific point of van Fraassen's attack on scientific realism I am interested in examining in this paper is an argument that I will call the argument from microphysics. It belongs to the scope of step 3. But since this step is partly linked to step 2, I will begin, in the next section, by analysing van Fraassen's treatment of the "cosmic coincidence" argument.

Principia, 12(1) (2008), pp. 49-71. 


\section{2. "Cosmic coincidences" and the infinite regress of explana- tions in science}

In his classic Between Science and Philosophy (1968), J. J. C. Smart put forward an argument for scientific realism that became known as "the cosmic coincidence argument". ${ }^{3}$ As I understand it, the argument is based on the effective existence of scientific theories capable of predicting correctly a broad range of phenomena by postulating unobservable mechanisms. It is claimed that the best (or perhaps only) philosophical explanation for such predictive success is the approximate truth of the theory, including its assertions about the putative unobservable entities and processes underlying the occurrence of the phenomena. As Smart famously remarks, if these entities and processes were not real

one would have to suppose that there were innumerable lucky accidents about the behavior of the things mentioned in the observational vocabulary, so that they behaved miraculously as if they were bought about by the nonexistent things ostensibly talked about in the theoretical vocabulary. (Smart 1968, p. 150-1)

Van Fraassen approaches this argument in a roundabout way. After disposing of the direct abductive arguments for scientific realism, he raises a "second objection" to such arguments:

even if we were to grant the correctness (or worthiness) of the rule of inference to the best explanation, the realist needs some further premiss for his argument. [...] So the realist will need his special extra premiss that every universal regularity in nature needs an explanation, before the rule will make realists of us all. (1980, p. 21; italics added.)

If the realist does indeed make such a demand, he is in obvious trouble, since it leads to an infinite regress of explanatory theories, as van Fraassen (effectively) notices on p. 24-5. To block this regress van Fraassen suggests that we recall the mediaeval nominalists and say:

that the observable phenomena exhibit these regularities, because of which they fit the theory, is merely a brute fact, and may or may not have an explanation in terms of unobservable facts 'behind the phenomena' it does not matter to the goodness of the theory, nor to our understanding of the world (1980, p. 24).

Principia, 12(1) (2008), pp. 49-71. 
Against this suggestion I would remark, first, that apparently no scientific realist has ever construed the demand for explanation as "unlimited" or "supreme", as van Fraassen asserts (p. 23). An explanatory scientific theory is not invalidated by our eventual, contingent inability to devise another theory capable of explaining the regularities postulated by the explanatory mechanisms of the former theory. The quest for explanation is open-ended, but not "supreme".

In the second place, if accommodation to a "nominalist" position were to become a general rule, it would be in tension with van Fraassen's own official position. Constructive empiricism, let us recall, is a moderate form of anti-realism, lying at the end of the spectrum that begins with Machian phenomenalism - a position which does indeed prescribe a generalised ban of explanatory theories. ${ }^{6}$

A more serious objection concerns van Fraassen's association of the "supreme" demand for explanation with the cosmic coincidence argument (and others arguments of the same kind, such as Putnam's "miracle" argument). That van Fraassen takes this demand for explanation as the main thrust of the argument is clear from the fact that immediately after suggesting the adoption of the nominalist stand he says: "Smart's main line of argument is addressed to exactly this point" (p. 24; my italics). He then sets about to offer his account of the argument. After quoting the relevant passage, he sums up his views in these words:

In other passages, Smart speaks similarly of 'cosmic coincidences'. The regularities in the observable phenomena must be explained in terms of deeper structure, for otherwise we are left with a belief in lucky accidents and coincidences on a cosmic scale (1980, p. 25).

I regard this construal as mistaken. Smart's argument explores the situations in which a non ad hoc explanatory theory is already available. It is argued, then, as I noticed above, that the predictive success of this theory cannot be adequately explained except by the (approximate) correspondence of its theoretical assertions with reality. According to the argument, a "cosmic coincidence" would be required to account for predictive success in the absence of such a correspondence, and not, as van Fraassen holds, to account for natural regularities eventually left unexplained. Thus, van Fraassen's construal confounds the issue of the explanatory success of the scientific theory (which is not central in the argument) with the issue of the explanatory success of the philosophical theory of scientific realism in accounting for the predictive success of certain nonphenomenological scientific theories. By diverting the import of the argument to the supreme demand for explanation of natural regularities, van Fraassen not

Principia, 12(1) (2008), pp. 49-71. 
only saddles the realist with an absurd position, but also fails to effectively rebut Smart's real argument. ${ }^{7}$

\section{Hidden variables in microphysics}

Although infinite regress is a sufficient, fatal objection to the "supreme" demand for explanation, van Fraassen raises a second, more technical objection to such a demand. This objection plays a central role in van Fraassen's criticism of scientific realism, since he believes it applies to the whole class of realist arguments based on abduction. Right at the beginning of his discussion of Smart's argument, van Fraassen announces:

I shall object to this line of argument [i.e. the supreme demand for explanation], as found in the writings of Smart, Reichenbach, Salmon, and Sellars, by arguing that such an unlimited demand for explanation leads to a demand for hidden variables, which runs contrary to at least one major school of thought in twentieth-century physics (1980, p. 23).

Before considering van Fraassen's argument, I shall briefly explain its scientific background to the non-specialist, a task that van Fraassen does not do in The Scientific Image, nor in his other publications on this issue. ${ }^{8}$

The whole dispute hinges on the issue of the incompleteness of quantum mechanics (QM), our basic theory of the structure of matter. Just after its inception, in the 1920's, doubts as to the capacity of the theory to describe completely the properties of physical objects were voiced by some of its own creators. These doubts derive from the peculiar way in which QM describes the states of physical objects. In classical mechanics, the state of an object is specified by the positions and momenta of its constituent particles. Given these numbers, the values of all dynamical magnitudes belonging to the object can be determined univocally. In contrast, when information about an object is maximal, its quantum mechanical state is described by a wavefunction (or, more generally, a state vector). Each wavefunction, however, yields the values of some, but not all physical magnitudes ordinarily considered as belonging to the object. Thus, on the face of it, QM fails to afford a complete description of the properties of the object. This conclusion is reinforced by the fact that the magnitudes whose values are not specified by a given wavefunction can, at any moment, be individually measured; and definite results are obtained, as in classical physics. This straightforward argument for incompleteness has encountered immediate opposition from some leading figures of quantum physics, such as Bohr and Heisenberg, who devised a series of

Principia, 12(1) (2008), pp. 49-71. 
counter-arguments based on semi-formal physical and philosophical considerations.

In an article published in 1935, Einstein, Podolsky and Rosen (EPR) put forward a rigorous, technical argument for incompleteness of QM. This argument triggered one of the most important debates in the history of physics, occupying a voluminous literature, and will not be examined in detail here. I will just offer a rational reconstruction of the argument, suitable to my present purposes. ${ }^{9}$ Einstein and his two collaborators pointed out that the quantum mechanical treatment of certain physical systems, composed of two spatially separated, non-interacting objects prepared together in a common source (where they did interact), exhibits a rather puzzling aspect. For such systems, measurements of a certain physical magnitude - let us call it $S$ - on each of the two objects afford strictly correlated results: if one is +1 , say, the other will be -1 , and vice versa. Now, although QM predicts the existence of this absolute correlation, it does not predict the individual measurement results. For the individual objects, $S$ is just one of those magnitudes whose values are not specified by the wave function describing the state in which the system is prepared. This implies that QM does not give any explanation for the correlation of the measurement results. This situation is entirely unprecedented in physics. Furthermore, if $\mathrm{QM}$ is taken as affording a complete description of the pair of objects, it will be incompatible with any explanation, except for some kind of non-local influence between the two branches of the experiment (object plus measurement apparatus), since the correlation cannot, upon the assumption of completeness, be rooted in individual S-values existing previously to the measurements, as would be the case in classical physics.

As it happens, however, the postulation of non-local actions is highly unwelcome in physics, for physical and methodological reasons. Locality, or the principle of local actions, is one of the basic tenets of contemporary physics, on which we should, in Einstein's opinion, "absolutely hold fast". ${ }^{10}$ Therefore, the only way of accounting for the EPR correlations is to take the quantum mechanical description of the correlated objects as being incomplete. Indeed, if it is possible to supplement the quantum mechanical description of the objects by adding certain variables, that additional information could, in principle, eliminate the indefiniteness of the values of property $S$ before measurement, making thus room for the classical explanation of the correlations - i.e., an explanation based on pre-existing S-values, determined when the objects interacted at their source.

Such putative additional variables became known as hidden variables ('hidden', because not belonging to QM), and the theories incorporating them as hidden-variable theories (HVTs). Notwithstanding the tremendous impact of the

Principia, 12(1) (2008), pp. 49-71. 
EPR argument, the idea of HVTs never gained wide acceptance among physicists. ${ }^{11}$ This fact was determined not only by the informal counter-arguments put forward by Bohr, Heisenberg and other defenders of the so-called "Copenhagen interpretation of QM", but also by a series of negative results obtained in the second half of the twentieth century.

These results against HVTs can be classified in two main groups. The first is formed by certain algebraic theorems showing that the addition of extra parameters to the quantum mechanical states may lead — given certain assumptions - to formal inconsistencies. The second group derives from the important research undertaken by John Bell in the early 1960's on correlated, EPR-type pairs of objects in which the correlation is not absolute. Bell has proved that any HVT capable of reproducing certain quantum mechanical empirical predictions is bound to be non-local. Local HVTs predict that a certain inequality ("Bell's inequality") is satisfied, whereas QM predicts that it is violated. Careful experimental tests performed in the following two decades - notably those conducted by Alain Aspect - confirmed the quantum mechanical predictions. Thus, any local HVT conflicts not only with QM, but also with empirical data. This shows, ironically, that the price for completing QM is precisely the violation of locality, the basic premise of EPR's incompleteness argument. But this is a very high price to be paid in physics, as I have already remarked. ${ }^{12}$

\section{Van Fraassen's argument from microphysics}

I have already quoted a passage from The Scientific Image in which van Fraassen asserts that the "unlimited demand for explanation leads to a demand for hidden variables, which runs contrary to at least one major school of thought in twentieth-century physics" (1980, p. 23). From the summary of the situation in microphysics given above, it is clear that the search for HVTs can be seen as motivated by the search for explanations for the EPR-Bell correlations. However, van Fraassen wastes ammunition here, since this holds even if the demand for explanation is not "unlimited", or "supreme". But this is a minor point.

A more serious problem with this argument — which I will call the argument from microphysics - concerns the explicit reason van Fraassen offers in The Scientific Image for rejecting the quest for hidden variables. It is true, as I have already remarked, that physicists belonging to the Copenhagen school strongly opposed the programme of hidden variables. It is also true that this school rapidly became orthodoxy in quantum mechanics. But this does not constitute, ipso facto, an ul- 
timate reason for rejecting the programme. A conflict with a school of thought no matter how influential - does not amount to an impossibility proof, of course. It is curious that van Fraassen did not appeal, in the argument presented in The Scientific Image, to the much more substantial objection deriving from the abovementioned theoretical and experimental results against HVT, which were hotly debated when the book was published. ${ }^{13}$

But I want to argue now that not even these results entail an ultimate ban on HVTs, and therefore that the quest for explanations in science is not thwarted by microphysics. The analysis of this point should take into account the extended treatment given by van Fraassen to the scientific part of argument from microphysics in latter publications. Of particular interest are the papers "EPR: When is a correlation not a mystery?" (1985b), which reappeared, in an expanded version, as chapter 10 of Quantum Mechanics (1991), and "The charybdis of Realism: Epistemological implications of Bell's inequality (1982), which was also re-published, with additions, in Laws and Symmetry (1989). In these texts van Fraassen proposes that in the history of science and philosophy one can find six types of explanation capable of rendering correlations unmysterious: chance, coincidence, co-ordination, pre-established harmony, logical identity, and common cause. ${ }^{14}$

Coincidence is distinguished from chance along Aristotelian lines: in a coincidence there are reasons, or causes, for the correlated phenomena, taken individually; but these causes are independent of each other. In the case of the EPR-Bell correlations, it is quite evident that neither chance nor coincidence are viable explanations, as van Fraassen correctly notices. So I will pass directly to the other explanatory options, beginning with the last, common cause.

In the context of the EPR-Bell correlations, common causes mean hidden variables, i.e. putative parameters capable of supplying the values not afforded by QM to the correlated magnitudes prior to measurement. With such values, it is trivial to devise an explanation for the correlations along entirely classical lines, by assuming that the two values have been jointly established when the two the objects still interacted, in their common source. This is exactly the reasoning of $E P R$, in the rational reconstruction of their argument that I proposed in the preceding section. However, the addition of hidden variables to QM faces the negative theoretical and experimental results mentioned in that section. In particular, any explanation for the correlations based on local hidden variables is ruled out by the experimental violation of the Bell inequalities. Van Fraassen appeals to this incontrovertible result to discard any attempt to explain the EPR-Bell correlations through common causes. But this is not a strictly valid move. Explanations through non-local HVTs remain possible, and this is a kind of common

Principia, 12(1) (2008), pp. 49-71. 
cause explanation, although entirely non-classical, and involving also elements of "co-ordination" (in van Fraassen's sense, to be explained below). Indeed, as is well known, David Bohm afforded a concrete example of a theory of this type in 1952. This theory has led to many important developments in microphysics in the following decades, among which one should count Bell's theorem itself. Bohm's programme of non-local HVTs remains active nowadays, having attained a remarkable degree of theoretical solidity. Like it or hate it, it cannot be discarded as inconsistent, incoherent or scientifically unfruitful. It is, thus, puzzling that van Fraassen gives no attention it in his writings. ${ }^{15}$

It is interesting to notice that Bohm's theory leaves open the exact nature of the non-locality involved, offering an additional margin of choice for those interested in devising a picture of physical reality (Chibeni 1997). If the hiddenvariables are regarded as controllable — an unlikely possibility, despite Bohm's initial expectations - the non-locality will be controllable (to use the distinction introduced by Shimony 1984b); if they are uncontrollable, the non-locality will be uncontrollable. In the latter event, there would be non-local influences, but no non-local signals. This leads directly to another kind of explanation in van Fraassen's list, coordination.

By co-ordination van Fraassen means "a correspondence effected by signals (in a wide sense): some energy or matter travelling from one location to another, and acting as a partial producing factor for the corresponding event" (1991, p. 350). He briskly rejects this kind of explanation in the case of the EPR-Bell correlations, on the allegation that the "experiments by Aspect and others leave no hope for co-ordination to explain the quantum mysteries". ${ }^{16}$ From the above discussion, it transpires that this is not the right conclusion to be drawn from the experiments. ${ }^{17}$ It is true that Aspect has shown that the Bell inequalities are violated even when the measurement events have space-like separation. This means simply that any eventual non-local influence postulated to account for the correlation must be superluminal. Now, there are in principle two ways of doing this: either by a non-local HVT, or by some non-local theory without hidden variables. I will comment briefly these two possibilities.

As to the possibility of explaining the correlations through a non-local HVT, we have just seen that, at least in the example already available — Bohm's theory - there is an option as to the kind of non-locality involved. In one of them, nonlocality is uncontrollable, and therefore not capitalisable for the transmission of signals (in the stricter, usual sense of the word). In the other, it is controllable, and therefore allowing the transmission of signals. If such signals are superluminal - as they would have to be, in virtue of Aspect's result -, matters get worse,

Principia, 12(1) (2008), pp. 49-71. 
since arguably this would entail a conflict with relativity theory. ${ }^{18}$ But even in this case one could not strictly say that "the recent experiments by Aspect and others leave no hope for co-ordination to explain the quantum mysteries", as van Fraassen says. If superluminal signals are indeed incompatible with relativity, there is, in principle, the possibility of replacing this theory. This would be a hard decision, no doubt, but it would not be the first, nor presumably the last, time that in science entrenched theories are replaced by new ones, under theoretical and empirical pressure.

Considering now the other alternative indicated in the penultimate paragraph, namely, devising an non-local explanation without hidden variables, the most natural way of implementing it is to take QM as it is - i.e. without any complements -, and imbed it into a realist interpretation. In this case, nonlocality would involve some process of transforming the indefinite values of the correlated magnitudes prior to the measurement into definite values, upon a measurement performed on any of the objects. ${ }^{19}$ Now, there are several proofs in the literature showing that this kind of non-local influence does not allow the possibility of sending superluminal signals. Therefore, here again, as in the case on a Bohmian theory with uncontrollable hidden variables, the fear of conflict with relativity is unfounded. This alternative has not received the same amount of attention in the literature as the programme of non-local HVTs. But this does not mean, of course, that it is not worthy of further inquiry, nor that it is not even worthy of mention, when a general inventory of logically possible alternatives becomes necessary, as in the present case..$^{20}$

It is instructive to digress a little to try to understand why van Fraassen does not consider this explanatory option. The same exercise may also help to explain van Fraassen's disregard for non-local HVTs. I begin by noticing that in The Scientific Image there is a section entitled "The principle of common cause", in which van Fraassen examines what he regards as a more precise formulation of the demand for explanation: Reichenbach's principle of the common cause. In the initial, informal rendering of the principle offered by van Fraassen, it says that "every statistical correlation [...] must be explained through common causes" (p. 26). This is followed by a formal, technical exposition of the principle. In both versions a crucially important qualification is omitted by van Fraassen: the exigency of explanation through common causes should not be taken absolute, for the correlation can, in principle, be explained by direct causal actions between the correlated objects or events. ${ }^{21}$ In The Scientific Image, van Fraassen gives no hint to his readers as to why he did not even consider this possibility. In the later texts under analysis here he does give a very substantial reason, as we have

Principia, 12(1) (2008), pp. 49-71. 
seen: by force of the Bell-Aspect result, direct causation would entail violation of locality. But now what is missing is a fuller exposition and discussion of the exact nature of the non-locality involved in each theoretical alternative, along with the indication, in each case, of the scientific reasons why non-locality would be unacceptable.

Apparently, van Fraassen's wholesale rejection of non-local explanations derives partly from the usual fear of conflict with relativity theory (a fear that he overestimates, as we have seen), and partly from his view that non-local influences, or actions, would mean, literally, "spooky action at a distance" — as Einstein once said - i.e., the possibility of "affect[ing] what happens at a distance without intervening causal chains" (van Fraassen 1991, p. 364; my italics). But perhaps this gloss of the idea is too strong. Someone who takes seriously the possibility of accounting for the quantum correlations by abandoning the principle of locality does not, ipso facto, lapse into the realm of the supernatural. The putative superluminal influences at work may, hopefully, be understood in purely physical terms, although in a presently unforeseeable way. ${ }^{22}$

Van Fraassen's fifth kind of explanation, "logical identity", is also analysed by him in terms of hidden variables. The idea would be, roughly, to regard the correlated magnitudes as functions of a third, independent magnitude, so that the correlation could be seen as deriving merely from the algebraic relations between these magnitudes. Van Fraassen correctly remarks that this will work as an explanation of the correlation between the measurement results only if "prior to measurement [this third magnitude] has a certain value, and the measurements merely reveal that value" (1991, p. 356). Since QM does not afford such a value, it is "hidden". Therefore, this account would, according to van Fraassen, fall prey to the algebraic results against HVTs, such as the famous Kochen-Specker theorem.

Having analysed this technical issue at length elsewhere (Chibeni 1997), I will here limit myself to two general remarks. First, although the algebraic results do, in fact, impose severe restrictions on HVTs, the precise nature of these restrictions is rather complex. Utmost care is needed, thus, not to overstate their implications. In this connection, I believe that van Fraassen's account does not underline a point that he knew very well, and even contributed to establishing: that the algebraic theorems are, as he himself aptly calls them, "limitative theorems" (1991, p. 357), rather than absolute impossibility proofs. Like any theorem, they have premises, and these can be questioned in a number of ways. Thus, a firm believer in explanations through "logical identity" does not necessarily runs afoul of inconsistencies, provided he appeals to one of the several tricks on sale

Principia, 12(1) (2008), pp. 49-71. 
in the literature: "contextual" hidden variables, van Fraassen's "de-occamization" strategy, etc. ${ }^{23}$

Secondly, by using the algebraic results to discard explanations through "logical identity" van Fraassen may pass a false message to his reader. By imposing certain limits to the introduction of hidden variables, these algebraic results have negative implications for explanations by "common causes" too, since, as we have seen, in microphysics hidden variables typically play the role of common causes. Furthermore, the Bell-Aspect result may also be seen as counting against "logical identity", since it imposes limits on (local) hidden variables. ${ }^{24}$ Thus, to regard hidden variables as providing a basis for explanation through "common causes" or "logical identity" seems to be just a matter of perspective. In fact, the complex (and controversial) partial superposition of premises and implications of all the results against HVTs (see Chibeni 1997) makes it difficult, if not impossible, to establish a one-one correspondence between kinds of explanation and negative arguments stemming from microphysics, as van Fraassen attempts to do. The fact, noticed above, that Bohm's HVT involves at once "common cause" and "co-ordination", affords further support to this point. Thus, the appraisal of the possibilities of explaining the EPR-Bell correlations by "common causes", "coordination" or "logical identity" is more complex than van Fraassen's discussion seems to imply.

This situation instantiates very well a perceptive philosophical remark made by Stairs in a paper in which he criticises the version of the argument from microphysics appearing in van Fraassen 1982 (in which, let us recall, the enumeration of the six kinds of explanation had not yet been introduced). Stairs rebuts van Fraassen's claim that the EPR-Bell correlations are unexplainable because common cause explanations are (supposedly) ruled out by the violation of the Bell inequalities by correctly pointing out that there may, in principle, be other kinds of explanation, and that, generally, "realism is not committed to specifying in advance the sorts of explanation that are acceptable. [...] It is, in part, by doing science that we find out how things are to be explained. Sometimes, new theories may lead to new sorts of explanations [...], and there is no reason to expect that philosophical reflection will establish what these forms will be like in advance of actual theorizing" (1984, p. 356).

As we have just seen, by ignoring this point van Fraassen has, in the subsequent development of his argument, artificially forced the analysis of the issue of the explanation of the quantum correlations into a six-place grid which does not do full justice to the actual development of microphysics. It is clear, in particular, that none of the three "classical" possibilities — common causes, co-ordination

Principia, 12(1) (2008), pp. 49-71. 
and logical identity — can be definitely ruled out solely by the Bell-Aspect or the Kochen-Specker results, singly or in conjunction. These results leave open the possibility of devising explanatory theories involving elements of the three kinds of explanation, provided certain theoretical concessions are made. Now, the neglect of this point may bias seriously the appraisal of the anti-realist argument from microphysics: it makes the case against explanations in microphysics look much stronger than it actually is.

This negative stand has pushed van Fraassen to the seemingly uncomfortable position of having to accept the only remaining way - in his own enumeration of possibilities - to account for the quantum correlations: pre-established harmony! Van Fraassen distinguishes two construals of pre-established harmony: the classical, Malebranche-Leibniz version, which appeals to "an Entity which [...] co-ordinates the two series of events 'from outside', or else, to admit that we have no explanation but refuse to consider the correlation mysterious nevertheless" (1991, p. 351, emphasis in the original). I shall not discuss whether this latter construal should properly be called pre-established harmony or not. What matters here is that van Fraassen's italics, coupled with the very title of his chapter/paper under analysis ("EPR: When is a correlation not a mystery?"), unequivocally indicate that this is, indeed, his favoured option. This impression is reinforced by these words (added in the 1991 version of the text), following immediately the phrase just quoted:

Taken in this sense, disdain on our part may be inappropriate, for it is an attitude that has often occurred in the history of science and is now perhaps forced upon us, if we are to maintain the completeness of physics. (1991, p. 351; my italics)

When van Fraassen resumes this topic, in the final section of the chapter/paper, he remarks that the word 'mystery' "is not merely descriptive - to call something a mystery is not so much a statement as a demand, a demand for explanation" (1991, p. 372). But, he adds, "[d]emands need not always be met". And he recalls us of two classical scientific demands that have been dismissed by the advancement of physics: the Aristotelian demand for a force capable of keeping projectiles in motion, and Newton's demand for a cause of gravitation. ${ }^{25}$ According to van Fraassen, the demand for this or that kind of scientific explanation is part of the "philosophical propaganda" of the age. And "[w]hen the propaganda gets into trouble, such an aim becomes more easily attainable if standards are lowered, if some why-questions are discarded" (1991, p. 372). The lesson he wants to draw is clear: it is high time for us to reject the demand for ex-

Principia, 12(1) (2008), pp. 49-71. 
planation of the EPR-Bell correlations. Let us take them as "brute facts" that need no explanation. ${ }^{26}$

We are, thus, back to the same point made by van Fraassen in The Scientific Image. Even the reference to the mediaeval nominalists reappears, at the end of the chapter, with the differences that now they are put in the company of the "British empiricists, the French positivists and conventionalists, and the Vienna and Berlin Circles", ${ }^{27}$ and that now the "nominalist" recommendation is not coupled to an explicit criticism of the use of abductive arguments for realist purposes; it is presented simply as a part of an "empiricist, anti-metaphysical tradition".

I do not intend here to assess the merits of philosophical "propaganda" or "traditions". My goal in this section was simply to argue that the scientific reasons van Fraassen offers for his choices are not waterproof. Although his analyses of the results against HVTs are incisive and illuminating on several aspects (whose discussion does not belong to the scope of the present paper), they make the prospects of explaining the EPR-Bell correlations look darker than they actually are. As I pointed out, the results do, indeed, impose severe constraints on the most natural explanations for these quantum correlations, but, provided we are willing to pay the appropriate price, the classical scientific ideal of explaining the natural "mysteries" can be retained as a valid and stimulating intellectual challenge.

\section{Concluding remarks}

To conclude, I would like to consider briefly several points of a more general scope. First, even if the strength of van Fraassen's argument from microphysics were not greatly diminished by the reasons I have indicated, its effect on scientific realism would be rather limited. For even if the EPR-Bell correlations were indeed unexplainable, scientific realists would still be left with a plethora of other phenomena for which science - including microphysics - has already offered plausible, coherent and non ad hoc explanations based on unobservable mechanisms. They could, thus, continue to capitalise on these explanations to defend their position by means of the cosmic coincidence and miracle arguments, for instance.

Secondly, if my interpretation of these arguments is correct, they depend not so much on the explanatory, as on the predictive power of certain theories postulating unobservables; so that whether or not the demand for explanations can be met in science should not be taken as the central issue in the debate over scientific realism.

Principia, 12(1) (2008), pp. 49-71. 
Thirdly, in The Scientific Image van Fraassen admits that the demand for explanations may lead to the discovery of new empirical regularities (p. 33), and that the principle of the common cause may have some role to play in science, but only as a "tactical maxim": it may afford "advice for the construction of theories and models" (p. 31) ${ }^{28}$ However, he holds that "if the resulting theory is then claimed to be empirically adequate, there is no claim that all aspects of the model correspond to "elements of reality"' (p. 31). I think everybody should acknowledge the heuristic role of the demand for explanations and, in particular, of the principle of the common cause, in empirical inquiry and in theory construction. But it seems to me that this is not their only role. In certain specific circumstances commonly found in contemporary science, the search for encompassing, coherent explanatory theories postulating unobservable entities typically leads to theories that also exhibit the kind of predictive power explored in the cosmic coincidence and miracle arguments, and therefore contributes to offering reasonable grounds for believing that such unobservable entities do, at least approximately, correspond to "elements of reality" (in EPR's famous expression).

Finally, the fact that physicists have not generally been deterred in their quest for explanations for the quantum correlations by the strong constraints imposed by the results against HVTs indicates that this classical goal of science is much more entrenched in the scientific community than van Fraassen seems to believe. Physicists not only generally ignore van Fraassen's "nominalist" recommendation, but also appear to show, in recent decades, a growing disregard with respect to the instrumentalist interpretation favoured by the Copenhagen school. Among philosophers of science, these anti-realist positions continue to have some sympathisers, as I noticed above in a footnote, but this is besides the point here. Van Fraassen's argument examined in this paper is explicitly an argument from microphysics: the alleged proscription of HVTs either by conflicts with school of thought in physics or by theoretical and experimental results in microphysics. And, as I have argued, none of these reasons is sufficiently strong to underpin van Fraassen's misgivings on the demand for scientific explanations, and therefore, indirectly, his anti-realist conclusions. ${ }^{2930}$

\section{References}

Bell, J. S. 1981. Bertlmann's socks and the nature of reality. Journal de Physique (colloque C2, supplément au n.3) 42: C2/41-61.

Butterfield, J. 1989. A space-time approach to the Bell inequality. In Cushing and McMullin 1989, p. 114-44.

Principia, 12(1) (2008), pp. 49-71. 
Chibeni, S. S. 1993. Descartes e o realismo científico. Reflexão 57: 35-53.

- 1996. A inferência abdutiva e o realismo científico. Cadernos de História e Filosofia da Ciência (série 3) 6(1): 45-73.

—. 1997. Aspectos da Descrição Física da Realidade. (Coleção CLE, vol. 21). Campinas: Centro de Lógica, Unicamp.

—. 1999. Le réalisme scientifique face à la microphysique. Revue Philosophique de Louvain $97(3-4): 606-27$.

- 2001. Indeterminacy, EPR and Bell. European Journal of Physics 22: 9-15.

- 2003. Hume on the principles of natural philosophy. Manuscrito 26(1) : 183-205.

- 2005a. A logico-conceptual analysis of the Einstein-Podolsky-Rosen argument. In Pietrocola, M. and Freire Jr., O. (eds.) Filosofia, Ciência e História: Michel Paty e o Brasil, uma homenagem aos 40 anos de colaboração. São Paulo: Discurso Editorial, p. 115-35.

- 2005b. A Humean analysis of scientific realism. In Guimarães, L. (ed.) Ensaios sobre Hume. Belo Horizonte: Segrac Editora, p. 89-108.

—. 2005c. Locke on the epistemological status of scientific laws. Principia 9(1-2): 1941. (http://www.cfh.ufsc.br/ principi)

—. 2006. Afirmando o conseqüente: Uma defesa do realismo científico (?!). Scientiae Studia 4(2): 221-49.

Churchland, P. M. and Hooker, C. A. (eds.) 1985. Images of Science. Chicago: University of Chicago Press.

Cushing, J. T. and McMullin, E. (eds.) 1989. Philosophical Consequences of Quantum Theory. Notre Dame, Indiana: University of Notre Dame Press.

D'Espagnat, B. 1983. In Search of Reality. New York: Springer-Verlag.

Dorling, J. 1987. Schrödinger's original interpretation of the Schrödinger's equation: A rescue attempt. In Kilmister 1987, pp. 16-40.

Fine, A. 1986. The Shaky Game: Einstein and the Quantum Theory. Chicago: The University of Chicago Press.

—. 1989. Do correlations need to be explained? In Cushing \& McMullin 1989, pp. 17594.

Hooker, C. A. (ed.) 1973. Contemporary Research in the Foundations and Philosophy of Quantum Theory. Dordrecht: Reidel.

Kilmister, C. W. (ed.) 1987. Schrödinger. Centenary Celebration of a Polymath. Cambridge: Cambridge University Press.

Kronz, F. M. 1988. EPR: The correlations are still a mystery. Philosophy of Science 55: 631-9.

Lahti, P. and Mittelstaedt, P. 1985. Symposium on the Foundations of Modern Physics. 50 Years of the Einstein-Podolsky-Rosen Gedankenexperiment. Singapore: World Scientific.

Lipton, P. 2004. Inference to the Best Explanation. 2nd. ed. London: Routledge.

Musgrave, A. 1985. Realism versus constructive empiricism. In Churchland \& Hooker 1985, p. 197-221.

Principia, 12(1) (2008), pp. 49-71. 
Paty, M. 1986. La non-séparabilité locale et l'objet de la théorie physique. Fundamenta Scientiae 7(1): 47-87.

—. 1988. La matière dérobée. Paris: Archives Contemporaines.

Penrose, R. \& Isham, C. J. (eds.) 1986. Quantum Concepts in Space and Time. Oxford: Clarendon Press.

Popper, K. R. 1972. Conjectures and Refutations. 4th ed., revised. London: Routledge and Kegan Paul.

Psillos, S. 1999. Scientific Realism: How Science Tracks Truth. London: Roudledge.

Redhead, M. L. G. 1983. Nonlocality and peaceful coexistence. In Swinburne 1983, p. 151-89.

Reichenbach, H. 1956. The Direction of Time. Berkeley: University of California Press.

Smart, J. J. C. 1968. Between Science and Philosophy. New York: Random House.

Stairs, A. 1984. Sailing into the Charybdis: Van Fraassen on Bell's theorem. Synthese 61: 351-9.

Shimony, A. 1984a. Contextual hidden variables theories and the Bell inequalities. British Journal for the Philosophy of Science 35: 25-45. (Reproduced in Shimony 1993, vol. II, p. 104-29).

- 1984b. Controllable and uncontrollable non-locality. In Proceedings of the International Symposium on the Foundations of Quantum Mechanics. Physical Society of Japan. (Reproduced in Shimony 1993, vol. II, p. 130-9.)

—. 1986. Events and processes in the quantum world. In Penrose \& Isham 1986, pp. 182-203. (Reproduced in Shimony 1993, vol. II, p. 140-62.)

- 1989. Search for a worldview which can accommodate our knowledge of microphysics. In Cushing \& McMullin 1989, p. 25-37. (Reproduced in Shimony 1993, vol. I, p. 62-76.)

—. 1993. Search for a Naturalistic World View. 2 vols. Cambridge: Cambridge University Press.

Swinburne, R. (ed.) 1983. Space, Time and Causality. (Synthese Library, vol. 157.) Dordrecht: Reidel.

Teller, P. 1989. Relativity, relational holism, and the Bell inequalities. In Cushing \& McMullin 1989, p. 208-23.

Van Fraassen, B. C. 1973. A semantic analysis of quantum logic. In: Hooker 1973, p. $80-$ 113.

- 1979. Hidden variables and the modal interpretation of quantum statistics. Synthese 42: $155-65$.

—. 1980. The Scientific Image. Oxford: Clarendon Press.

-. 1982/1989. The Charybdis of realism: Epistemological implications of Bell's inequality. Synthese 52: 25-38. Reproduced, with additions, in Cushing and McMullin 1989, p. $97-113$.

Principia, 12(1) (2008), pp. 49-71. 
- 1985a. Empiricism in the philosophy of science. In Churchland \& Hooker 1985, p. 245-308.

—. 1985b. EPR: When is a correlation not a mystery? In Lahti \& Mittelstaedt 1985, p. 113-28.

- 1989. Laws and Symmetry. Oxford: Clarendon Press.

—. 1991. Quantum Mechanics: An Empiricist View. Oxford: Clarendon Press.

\title{
Keywords
}

van Fraassen, scientific realism, scientific explanation, abduction, microphysics, quantum mechanics.

\author{
Silvio Seno Chibeni \\ Department of Philosophy \\ State University of Campinas (Unicamp) \\ Brazil \\ chibeni@unicamp.br
}

\begin{abstract}
Resumo
O objetivo principal deste artigo é rebater um argumento contra o realismo científico formulado por van Fraassen a partir de considerações teóricas acerca da microfísica. Ao longo de seu ataque geral ao realismo científico, van Fraassen propõe, em oposição aos realistas científicos, que tomemos certas regularidades naturais como "fatos brutos", que não requerem explicação em termos de uma realidade inobservável subjacente. $\mathrm{O}$ argumento da microfísica aqui examinado baseia-se na alegação de que na microfísica, em particular, a exigência de explicações científicas desse tipo leva à exigência de teorias de variáveis ocultas. Mas tais teorias, diz van Fraassen, "vão contra pelo menos uma grande escola de pensamento na física do século XX". Neste artigo mostra-se detalhadamente que tal argumento não representa um obstáculo incontornável ao realismo científico, nem mesmo quando são levados em conta, não um mero conflito com certa escola de pensamento, mas diversos resultados teóricos e experimentais de limitação às teorias de variáveis ocultas na microfísica.
\end{abstract}

\section{Palavras-chave}

van Fraassen, realismo científico, explicações científicas, abdução, microfísica, mecânica quântica.

Principia, 12(1) (2008), pp. 49-71. 


\section{Notes}

${ }^{1}$ For an exposition and defence of the classical notion of explanation, see Salmon 1980. Aligning himself with this notion, Einstein asserted, in 1919: "When we say that we have succeeded in understanding a group of natural processes, we invariably mean that a constructive [i.e. explanatory] theory has been found which covers the processes in question" (1954, p. 228).

${ }^{2}$ In Part II of Laws and Symmetry (1989), van Fraassen endeavours to strengthen his case against the direct application of abductive arguments by way of a very technical analysis. I find the informal arguments advanced in The Scientific Image much more incisive.

${ }^{3}$ The argument dates back to, at least, Descartes; see The Principles of Philosophy, especially paragraph IV.205. For an analysis of Descartes's arguments pro and con scientific realism, see Chibeni 1993.

${ }^{4}$ In order not to fall prey to an obvious objection, the argument needs refinement. The predictive success that really counts here is that which has been called "strong predictive success", i.e. success in predicting kinds of phenomena that have not been explicitly taken into account when the theory was devised (Carrier 1991, 1993; Psillos 1999, chap. 5; Leplin 1997). In other words, predictively successful, but ad hoc theories lack adequate credentials for being taken as approximately true. This point has been emphasized by many authors, and will not be discussed here. (See, for instance, Descartes, Principles, III.42; Musgrave 1985, p. 210.)

${ }^{5}$ This point has been made by Popper (1972, chap. 3) and Musgrave (1985, section III), among others.

${ }^{6}$ I should emphasise that I am not claiming that van Fraassen has explicitly advocated such a wholesale ban of explanatory theories, but only that in proposing that we renounce the quest for explanations for an important class of physical phenomena he is effectively leaning towards this position.

${ }^{7}$ Elsewhere, I have argued that van Fraassen's account of Putnam's "miracle" argument suffers from a similar defect: due to misinterpretation, the real argument is left without proper rejoinder (Chibeni 1996, 1997, 2006; see also Musgrave 1985, p. 201, Lipton 2004, p. 170, and Psillos 1999, p. 96-7).

8 This topic receives extensive treatment in van Fraassen 1991 and 1985b, but these publications are much too advanced for the general reader. For my own analyses, and references to the specialised literature, see Chibeni 1997, 1999, 2001 and 2005a.

${ }^{9}$ For more details, see Chibeni 1997 and 2005a.

${ }^{10}$ Einstein 1949, p. 85; see also Fine 1986, p. 103 and Howard 1985, p. 186.

${ }^{11}$ In fact, not even Einstein liked the idea of solving the apparent incompleteness of QM through the addition of hidden variables; he expressed the hope of a total reformulation of our theoretical framework for microphysics. For the purposes of the present analysis, however, no substantial loss of generality occurs in discussing the issue in terms of hidden

Principia, 12(1) (2008), pp. 49-71. 
variables. The essential point in dispute is the possibility of framing a theory capable of affording a complete value assignment to the physical quantities.

${ }^{12}$ Besides these two main kinds of results against HVT, there are also certain "quasialgebraic" theorems, proved by Heywood and Redhead, and Greenberger, Horne and Zeilinger in the 1980's, showing that local HVTs may, independently of the Bell inequalities, led to inconsistencies. See Chibeni 1997 for a detailed, comparative analysis of all these results against HVTs.

${ }^{13}$ In The Scientific Image the only (unnamed) reference to the Bell inequalities occurs in a cryptic passage on p. 30. That in this book van Fraassen did not explore this mass of scientific evidence favourable to his position is rendered more puzzling by the fact that he participated directly in the debate, as his more technical works cited below plainly attest.

${ }^{14}$ Van Fraassen 1991, sect. 4; 1985b, sect. I; 1989, Appendix (this appendix is one of the additions made to the initial version of the text (1982), which contained no reference to the six kinds of explanation). For simplicity, from this point on I will refer exclusively to page numbers of the extended versions.

${ }^{15}$ There is no reference at all to Bohm in Quantum Mechanics; in The Scientific Image he is mentioned en passant (p. 125), but in connection with another subject. It is also puzzling that the available, concrete possibility of explaining the Bell correlations through a non-local HVT is not mentioned in the perceptive criticism of the initial version of van Fraassen's argument from microphysics made by Allen Stairs (1984). Stairs limits himself to pointing out, generically, that the abandonment of non-locality would, in principle, open up the possibility of explaining the correlations.

${ }^{16}$ Van Fraassen 1991, p. 351. Interestingly, in the earlier versions of this text (1985b, 1982 and 1989) this assertion assumed a weaker form: "experiments ... leave little or no hope for co-ordination to explain the quantum mysteries" (italics added). This weaker thesis is compatible with the interpretation of the implications of the experiments I am proposing in the present article. I have chosen to direct my criticism to the stronger version because it is the last - and therefore, supposedly, more matured - version offered by van Fraassen.

${ }^{17}$ A direct criticism of this conclusion of van Fraassen's was made by Kronz (1988), who seems to be one of the few authors who have explicitly criticised the links intended by van Fraassen between the violation of the Bell inequalities, the limits to explanation and anti-scientific realism - in other words, what I call the argument from microphysics. Another important criticism of van Fraassen's attempt to refute realism by evoking the Bell inequalities is found in Stairs 1984 (see below).

${ }^{18}$ This point is controversial, however. For a detailed analysis, see Redhead 1983.

${ }^{19}$ Contrasting with this, in a HVT, unknown, but pre-existing definite values, are changed as a result of a distant measurement.

${ }^{20}$ For references and a defence of this line of research, see Shimony 1986, 1989 and

Principia, 12(1) (2008), pp. 49-71. 
Chibeni 1997, 1999.

${ }^{21}$ Reichenbach (1956) also omits this qualification, but it is clear that explanations through direct causal action are trivially excluded in the specific situations he discusses. For a careful analysis of this point, in the specific context of QM, see Butterfield 1989.

22 There is a detectable tendency among students of the foundations of quantum mechanics to become more sympathetic to non-locality, overcoming gradually Einstein's fears that this would mean the bankruptcy of physics. As a typical example, see the wellinformed defence by Michel Paty of the thesis that, given the recent developments in microphysics, it is time to explore seriously the prospects of a non-local physics (cf., in particular, Paty 1986, 1988). Taken in isolation from other texts of his, these words of van Fraassen would express perfectly the stand favoured in this footnote: "Today Bell's inequality argument makes the point that certain quantum mechanical phenomena cannot be accommodated by theories which begin with certain traditional assumptions. This vindicates, a half century after the fact, the physicists' intuition that a radical departure was needed in physical theory" (van Fraassen 1985a, p. 270).

${ }^{23}$ For a detailed analysis of "contextualism" in microphysics, see Chibeni 1997, where I argue that in the EPR-Bell systems contextualism amounts to non-locality. For van Fraassen's proposal of circumventing the algebraic results by breaking the usual one-toone correspondence between physical magnitudes and operators in the Hilbert space, see his 1973 and 1979. (Notice, however, that in note 7 of chapter 10 of his 1991 van Fraassen warns that he has never "advocated" this proposal, but only "described" it.)

${ }^{24}$ Shimony (1984a) has contended that the Bell inequalities can be generalized such as to apply to any physical system whatsoever (even to a single body). This proposal has been taken up by other authors, leading to an interesting debate. For references and discussion, see Chibeni 1997, sect. 6.4.

${ }^{25}$ Arthur Fine makes this same point in a paper belonging to his post-realist phase (Fine 1989). Kronz (1988) criticises, on physical and philosophical grounds, the intended parallel between the cases of inertia and of the EPR-Bell correlations.

${ }^{26}$ Paul Teller (1989) and Bernard d'Espagnat (1983) are among the few philosophers of science who have expressed sympathy to this "nominalist" stand.

27 This is not the place to dispute the ascription of anti-realism to such a heterogeneous group of philosophers (which van Fraassen has enlarged gradually: the 1985 version of the paper included only the "British empiricists"). But I cannot refrain to observing that such an ascription is clearly untenable at least in the case of Locke (see Chibeni 1985c); and that it is quite problematical in the case of Hume (Chibeni 1985b, 2003). Also, it does not seem that any of the mentioned philosophers has advocated van Fraassen's "nominalist" stand toward empirical correlations, an extreme anti-realist position championed by Mach, as I remarked in section 1; but curiously Mach is not included by van Fraassen in the list of his predecessors.

${ }^{28}$ In the chapter of Quantum Mechanics I am analysing, van Fraassen omits reference to

Principia, 12(1) (2008), pp. 49-71. 
these positive side effects of the realist quest for explanations.

${ }^{29}$ Such conclusions are put in a strong-looking form in "The charybdis of realism ..." (1982/1989): "Concerning epistemic realism I shall argue that, given one plausible way to make it precise, it is refuted by the Bell's inequality argument" (1989, p. 97). 'Epistemic realism' is defined by van Fraassen as the view according to which "Reasonable expectation of future events is possible only on the basis of some understanding of (or, reasonable certainty about) causal mechanisms that produce those events" (1989, p. 98; italics in the original). This notion of realism is not immediately comparable to the usual notion in the literature, and which has been nicely explicated by van Fraassen in The Scientific Image. This shift of target exposes van Fraassen's arguments in the paper to several objections; see Stairs 1984 and Chibeni 1997.

30 This article is a revised and enlarged version of a manuscript entitled "Van Fraassen e os limites da exigência de explicações na ciência", read at the "XI Encontro da ANPOF" (Salvador, 2004). I am especially grateful to Michel Ghins and Harvey Robert Brown for many helpful comments on the penultimate version of this paper, presented at the Fifth International Principia Symposium (Florianópolis, 2007).

Principia, 12(1) (2008), pp. 49-71. 